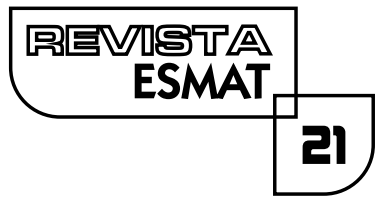

\title{
O CORPO DA MULHER E A MOBILIDADE SOCIAL: IMPACTOS NAS MIGRAÇÕES E TRÁFICO DE MULHERES
}

WOMEN'S BODY AND SOCIAL MOBILITY: IMPACTS ON MIGRATION AND WOMEN'S TRAFFICKING

Adriana Ferreira Serafim de Oliveira

Doutora em Educação, pela Unesp. Mestrado em Direito. Pós-Graduada em Políticas e Relações Internacionais. Bacharela em Direito. Licenciada em Letras. Professora conteudista. adrianaferserol@hotmail.com

Patrícia Tuma Martins Bertolin

Doutora em Direito do Trabalho, pela Universidade de São Paulo, Brasil. Professora Doutora da Universidade Presbiteriana Mackenzie, SP. ptmb@uol.com

Maria Esther Martínez Quinteiro

Doutora em Filosofía y Letras, pela Universidad de Salamanca, Espanha. Professora Doutora da USAL. Professora Titular da Universidade Portucalense Infante D. Henrique. est@usal.es

\section{RESUMO}

No decorrer da História da humanidade, as sociedades se acostumaram a vigiar, limitar, educar, tutelar e punir o corpo da mulher como se o ser humano feminino fosse incapaz de gerenciar sua individualidade e autonomia. A educação das subjetividades geralmente é conectada com o regime político dos Estados; contudo, em relação ao gênero feminino, além do próprio Estado, a sociedade da qual se é parte personifica o inquisidor do modo de ser e estar da mulher socialmente. Essa dinâmica social acaba perdendo intensidade em países democráticos, pois são territórios que permitem o cunho e debates quanto aos direitos fundamentais, que incluem temas sensíveis ao tecido social. $\bigcirc$ presente artigo analisou a mobilidade social do gênero feminino a partir da metade do século $X X$, o fenômeno do tráfico de mulheres e as migrações que podem levar a esse tipo de tráfico. Para tanto, o estudo valeu-se da revisão bibliográfica no campo das ciências humanas, sociais e jurídicas.

PALAVRAS-CHAVE: Mobilidade Social das Mulheres. Migrações. Tráfico de Mulheres. 


\section{ABSTRACT}

Throughout the History of humanity, the societies have become accustomed to guarding, limiting, educating, protecting, and punishing the woman's body as if the female human being was incapable of managing her individuality and autonomy. The education of subjectivities is usually connected with the political regime of the States, however, in relation to the feminine gender, besides the State itself, the society of which it is a part personifies the inquisitor of the way of being of the woman socially. This social dynamic ends up losing intensity in democratic countries, because these are territories that allow the construction and debate of fundamental rights, which include sensitive themes of social skin. The present article analyzed the social mobility of women from the middle of the twentieth century, the phenomenon of trafficking in women and the migrations that can lead to this type of trafficking. To do so, the study was based on a bibliographical review in the field of human, social and legal sciences.

KEYWORDS: Social Mobility of Women. Migrations. Traffic of Women.

\section{INTRODUÇÃO}

A educação do corpo e das subjetividades está atrelada ao regime político adotado por um Estado e ao que é esperado pelo imaginário social com relação a uma pessoa, como se estivéssemos fadados a um destino certo. A flexibilidade na educação corporal formal e não formal de uma sociedade funciona como uma mola tensora encolhida ou estendida em seus valores, paradigmas e conceitos.

Numa democracia, o poder simbólico dá lugar às críticas e aos questionamentos, propiciando que seus cidadãos desfrutem da vida cívica e exprimam seus anseios livremente, respeitando regras de convivência e recebendo o respeito por quem são.

As raízes sedimentadas do patriarcalismo ainda dificultam a mobilidade das mulheres na vida pública em consonância com seus anseios, pois subsistem costumes culturais e sociais, os quais informam que o lugar social das mulheres é determinado pela natureza e não uma construção secular da inferioridade feminina perante o masculino, conforme exprimem os ensinamentos bourdianos.

Na história, que também é uma história da tutela dos corpos, as mulheres foram e ainda são associadas aos afazeres domésticos e excepcionalmente aos espaços públicos, paradigma que vem sendo desconstruído desde a metade do século $X X$. 
O foco do estudo recai sobre a moral social sobre o corpo feminino que impacta na mobilidade das mulheres em sociedade e reflete nas migrações femininas e consequentemente no tráfico de mulheres.

\section{A MULHER E A MOBILIDADE SOCIAL}

Rubin (2017) propõe uma reflexão em sua literatura acerca das mulheres sobre a questão da natureza e da gênese da opressão e da subordinação social destas, considerando que as causas da opressão delas constituem a base do que deve ser modificado para tornar possível uma sociedade sem hierarquia de gênero em convivência no mínimo respeitosa.

A história demonstra que geralmente a opressão das mulheres decorre da agressão e da dominação masculina, inatas e intergeracionais. A Antropologia, a partir dos Estados Unidos, desde a década de 1970, questionou a universalidade da opressão às mulheres, concluindo que a desigualdade não é natural e acaba por aparecer em estreita conexão com o controle da sexualidade feminina e a instituição do ideal heterossexual'.

Esse poder invisível trata-se do poder simbólico e referenda a base do patriarcalismo ${ }^{2}$, ainda com raízes vigorosas ou sedimentado fortemente nas sociedades contemporâneas. É um poder não visto e silencioso, que o pensamento bourdiano discorre sobre situações em que este poder é ignorado, conforme a citação seguinte:

[...] o poder simbólico é, com efeito, esse poder invisível o qual só pode ser exercido com a cumplicidade daqueles que não querem saber que the estão sujeitos ou mesmo que o exercem (BOURDIEU, 1989, p. 7-8).

Com o passar do tempo, uma simbologia inscreveu-se nas sociedades para a permissividade unânime e longeva do conceito de espaço público destinado aos homens e, na contramão, a crença na fragilidade feminina foi reforçada. De acordo com os ensinamentos dos autores visitados, em quaisquer dos períodos históricos da humanidade, sob as mais variadas justificativas. O poder simbólico é um poder de construção da realidade que tende a estabelecer uma ordem gnosiológica em relação ao mundo (BOURDIEU, 1989, p. 9).

I A filósofa política estadunidense Carole Pateman constatou que os homens exercem o direito de acesso regular aos corpos das mulheres historicamente pela instituição familiar (PATEMAN, 1993).

2 Segundo Saffioti (2015, p. 57), o Patriarcado é uma forma de expressão do poder político que não se refere ao mundo público, mas suas hierarquias e sua estrutura de poder contaminam toda a sociedade. 
Para o mesmo autor, a dominação masculina é uma forma particular de violência simbólica, compreendendo o poder que demonstra significações, impondo-as como legítimas, de modo a dissimular as relações de força que sustentam a própria força, a ordem estabelecida, com suas relações de dominação, seus direitos e suas imunidades, seus privilégios e injustiças (Ibidem, p. 2-3).

A lógica bourdiana explica que a causa disso é que o mundo social constrói a realidade sexuada, com divisões sexualizantes do espaço público, fazendo com que a diferença biológica entre as anatomias dos órgãos sexuais masculinos e femininos sejam justificativas naturalmente explicáveis da diferença social produzida entre os gêneros, atingindo as relações da mobilidade social feminina (BOURDIEU, 2002, p. 3 e passim).

As considerações das diferenças entre homens e mulheres como inerentes à natureza, de acordo com os ensinamentos bourdianos, foram construídas socialmente no decorrer do tempo e espaço, e as escolhas orientadas pelos donos do poder social acentuaram diferenças e sombrearam semelhanças. Segundo Beauvoir (2009), as diferenças biológicas entre os gêneros serviram de fundamento equivocado para o confinamento das mulheres em suas casas, impedindo-se que elas pudessem participar ativamente da vida pública.

Nesse sentido, as mulheres foram excluídas da participação democrática na construção das sociedades ocidentais, modernas e pós-modernas. Atualmente, estamos ainda em uma sociedade ocidental construída na desigualdade entre os gêneros, onde os espaços públicos foram construídos com a predominância cultural do masculino no discurso.

Seguramente vários paradigmas sociais em relação ao espaço social que as mulheres podem ocupar foram desconstruídos, especialmente a partir da metade do século $X X$, com a movimentação das organizações feministas e as conquistas em matéria de direitos humanos no texto da Carta das Nações Unidas, de 19453, que dispararam outras rupturas que se seguiram na área jurídica no bojo de tratados internacionais e nos ordenamentos jurídicos internos quanto aos direitos fundamentais.

\section{AS MIGRAÇÕES E O TRÁFICO DE MULHERES PARA PROSTI- TUIÇÃO E TRABALHOS FORÇADOS}

O tráfico de mulheres é verificado no cenário internacional desde meados do século XIX, ligado à ideia de comercializar mulheres para exploração sexual. Essas

3 A diplomata brasileira Bertha Lutz esteve entre as poucas mulheres presentes na cerimônia de assinatura do documento fundador das Nações Unidas, em San Francisco, nos Estados Unidos, no ano de 1945. Ela foi uma das responsáveis por constar a palavra "mulher" nesse tratado internacional, texto que menciona a igualdade entre homens e mulheres (OLIVEIRA, 2020). 
noções, do senso comum de mercantilizar o sexo, foram formuladas ao longo do tempo e persistem na atualidade, apresentando consequências danosas principalmente para comunidades pobres ao redor do Planeta e implicações em termos de raça e gênero.

Conforme Kempadoo (2005), os tratados internacionais lidaram desde o fim do século XIX e início do XX com essa problemática, ao surgirem no cenário internacional mulheres trabalhadoras migrantes. A criação da Liga das Nações, em 1919, tratou dessa realidade inicialmente, sendo precursora do Tratado das Nações Unidas para a Supressão do Tráfico de Pessoas e a Exploração da Prostituiç̧ão de Outros, de 1949.

A mesma autora ensina que o tráfico se engendrou sobre a migração de muIheres sozinhas ao exterior e sobre a captura e escravização delas para prostituição em terras estrangeiras. $\bigcirc$ paradigma da existência de uma sociedade moral subjacente ao cristianismo, junto com a política do abolicionismo da escravidão negra e do movimento pelo sufrágio feminino na Europa e nos Estados Unidos, ajudou a formar o conceito de "tráfico de pessoas".

As pressões feministas ocidentais euro-americanas de classe média que combatiam a prostituição de mulheres brancas originaram uma corrente radical das relações sociais que prioriza as relações de gênero. Essa perspectiva liga o tráfico exclusivamente à prostituição, vista por sua vez como a pior forma de opressão patriarcal e a forma mais intensa de vitimização de mulheres (KEMPADOO, 2005, p. 57).

A premissa central dessa corrente feminista diz que a prostituição é "assédio, abuso e violência sexual", e as mulheres, coletivamente, vítimas das ideias sexistas. Ainda, considera que a indústria global do sexo força as mulheres à prostituição, mantendo-as em escravidão sexual, violando seus direitos e integridade corporal.

Essa corrente supõe que as mulheres nunca entram livremente em relações sexuais fora do sentimento "amor" ou do desejo sexual autônomo, considerando que elas são traficadas e forçadas à prostituição mediante o exercício do poder e do controle que homens podem exercer sobre suas vidas e seus corpos.

Do ponto de vista dessa corrente feminista, as consideradas instituições patriarcais (família, casamento e prostituição) podem ser definidas como violência, estupro e abuso com relação às mulheres, pois as que participam dessas instituições são enganadas pelo poder e privilégio social masculino, sendo que a universal liberação feminina pode ocorrer pela abolição dessas instituições que sustentam o patriarcado (Ibidem, p. 58) ${ }^{4}$.

4 A francesa Luce Irigaray (2017, p. 193) vai mais além, ao afirmar que "nessa nova matriz da História [nas sociedades que conhecemos], na qual o homem engendra o homem como seu semelhante, a mulher, a filha, a irmã só têm valor enquanto servem como possibilidade de relações entre homens, em benefício deles." Afirma ainda que o uso e o comércio de mulheres sustentam o "reino" masculino. 
A mesma autora ensina que a perspectiva da "escravidão sexual feminina" está historicamente ligada à Europa Ocidental e à América do Norte, e aos movimentos reformistas de mulheres de classe média originados nessa parte do mundo. Essa posição feminista contra a prostituição impõe uma lógica particular burguesa e imperialista às primeiras campanhas contra o tráfico, e pode ainda ser encontrada no movimento contemporâneo das mulheres dos Estados Unidos da América, algumas das quais se alinham com ideologias e agendas políticas cristãs conservadoras.

A abordagem do tema é crítica, e a autora nomeou como perspectiva feminista de terceiro mundo, a qual toma o tráfico como discurso e prática emergentes das interseções de relações do poder estatal, capitalista, patriarcal e racializadas em sua atuação. O patriarcado é visto como uma das relações de dominação que condicionam as vidas das mulheres, e não a única, nem necessariamente a principal (KEMPADOO, 2005, p. 60-6I).

Considera-se que racismo, imperialismo e desigualdades internacionais também configuram as vidas das mulheres. Além disso, enquanto o patriarcado significa a degradação de feminilidades em todo o globo, onde o trabalho e a vida das mulheres são concebidos, de diversas maneiras, nos discursos hegemônicos como menos valiosos que os dos homens e a serviço dos interesses sexuais masculinos, e as mulheres são muitas vezes definidas e tratadas pelos Estados como cidadãs de segunda classe ou como propriedades dos homens.

Em outra perspectiva, entende-se que são concebidas como sujeitos atuantes, autodeterminados e posicionados de maneira diferente, capazes não só de negociar e concordar, mas também de conscientemente opor-se e transformar relações de poder, estejam estas enraizadas nas instituições de escravidão, prostituição, casamento; no lar ou no mercado de trabalho. A atuação e a atividade feminina podem, então, apresentar-se de diversas maneiras, às vezes reinscrevendo e às vezes contestando a dominação e o controle do masculino sexualizado, dependendo de condições históricas e contextos culturais específicos.

Entende-se, ademais, que essa atuação pode ligar-se às vezes a estratégias de sobrevivência ou de geração de renda, estratégias que envolvem energias e partes do corpo sexualizadas, assim comparáveis a outros tipos de trabalho produtivo e, como tais, definidas como "trabalho sexual", embora tomando cuidado com a análise das atividades econômicas sexuais, devidamente contextualizadas e historicizadas. De qualquer maneira, levando em consideração que a atuação e o trabalho sexual, o envolvimento em indústria sexual e em trabalho sexual no exterior aparecem como possibilidades a que as mulheres se dedicam voluntária ou conscientemente, de acordo com parâmetros culturais, nacionais ou internacionais específicos.

Segundo Lagarde y de los Ríos (20 I I , p. 565): 
la prostituta es la mujer social y culturalmente estructurada em torno a su cuerpo erótico, em torno a la transgresión. Em um nível ideológico-simbólico, em esse cuerpo no existe la maternidade. La prostituta como grupo social disocia em su cuerpo la articulación entre los elementos básicos de la unidad genérica, de la condición feminina. La prostituta concreta la escisión de la sexualidade feminina entre erotismo y procreación, entre erotismo y maternidade, fundamentos sociales y culturales de signo positivo del género feminino.

Vale observar que a autora mexicana considera tanto a prostituição quanto a maternidade como sendo alguns dos "cativeiros das mulheres", sustentando que a condição das mulheres em geral se estrutura sobre dois eixos: sua sexualidade e sua relação com o poder (LAGARDE Y DE LOS RÍOS, 20 I I , p. 64).

Legardinier (2009), em seu entendimento, observa que "é comum tentar explicar a prostituição com base nas pessoas prostituídas, a ponta visível do iceberg", afirmando que ela "é, antes de tudo, uma organização lucrativa, nacional e internacional, de exploração sexual do outro" (p. 198).

A mesma autora entende que

a análise feminista considera a prostituição a situação mais extremada relação de poder entre as categorias de sexo. Transformadas em objetos e então sujeitas à violência, as mulheres são coisificadas em prol da sexualidade irresponsável dos homens (LEGARDINIER, 2009, p. 198).

Assim, em lugar de definir a própria prostituição como uma violência inerente contra as mulheres, são as condições de vida e de trabalho em que as mulheres podem se encontrar no trabalho do sexo, e a violência e o terror que cercam esse trabalho num setor informal ou subterrâneo violador dos direitos das mulheres, portanto, considerados como tráfico (Ibidem, p. 63-65).

A massificação da construção de que a mulher é colocada no lugar social de sexo frágil, na não equidade entre homens e mulheres nas sociedades, foi estudada por Castilho (2008), dois anos após a criação da Lei n | | 340, de 2006 (Lei Maria da Penha), no discurso de sentenças judiciais em que mulheres foram vítimas. As considerações da autora dão conta de que as decisões judiciais demonstraram a subsistência da concepção da mulher como sexo frágil, do seu papel tradicional no contexto familiar e quanto à prostituição; nessa construção social, é inadmissível que a mulher exerça a prostituição por livre e espontânea vontade; entretanto, ao mesmo tempo, as sentenças mostram que não houve muita preocupação com o sujeito "mulher", os porquês que as levaram a prostituir-se.

A maneira de essa mulher ser, de certa forma, serve para reprovar com menos rigor a conduta de quem foi acusado; e mesmo o trabalho sexual não sendo 
crime, produz a semelhante estigmatização social reservada aos criminosos, pois o juiz de direito, ao sentenciar esses casos, acaba por confirmar a ideia do imaginário social de que mulheres pobres e com pouca instrução são as que servem ao mercado do sexo, pautando a solução do problema na melhoria das condições de educação, emprego e saúde, ou seja, a problemática é resolvida aplicando políticas públicas que conferem a esses sujeitos os direitos fundamentais elencados (CASTILHO, 2008, p. 120-I22).

Nesse contexto, Schettini (20II) debate as ideias da feminista americana Emma Goldman ${ }^{5}$, que discorreu sobre as causas da prostituição, do tráfico, do sistema de gigolagem, da corrupção policial e das leis moralizadoras; entretanto, não confundia o conhecimento produzido sobre as prostitutas naquele momento, carregado de preconceitos e moralismos com a experiência das mulheres da classe trabalhadora que exerciam a prostituição.

Nos ensinamentos da autora, Goldman reinterpreta essa realidade à luz de seu pensamento libertário, atribuindo o comércio de mulheres às causas econômicas associadas à urbanização, à imigração e à industrialização, somando-se a inferioridade social das trabalhadoras. Exemplifica com a questão da trabalhadora doméstica, a qual nunca tem direito sobre si mesma, e com a questão sexual, que faz referência ao estado de ignorância permanente em que as mulheres já foram mantidas com relação à sua natureza, aos seus instintos e ao seu corpo (SCHETTINI, 20I I, p. 274).

Schettini (200I) acrescenta que, para Goldman, a questão da prostituição provoca outras reflexões, como a exploração sexual comparada à exploração da classe trabalhadora, e a "venda do corpo" possibilitaria colocar o casamento no mesmo patamar que a prostituição, pois em ambos os casos o tratamento dispensado às mulheres era o de mercadoria. Ainda, as mulheres que exerciam o comércio sexual eram vistas como vítimas e culpadas ao mesmo tempo e quanto às leis a esse respeito, a partir da metade do século XIX houve a regulamentação de casas de tolerância em vários países ocidentais, criminalizando a figura do gigolô; entretanto, mais vitimizando as prostitutas que propondo regulamentações.

Nesse ponto, vale provocar o questionamento a respeito do corpo da mulher e sua mobilidade social. Se o corpo da mulher pertence a ela própria, e não ao Estado, nem ao marido e muito menos à igreja, por que a mulher não é bem-vista se dispuser de seu próprio corpo, trabalhando em casas de tolerância?

A esse respeito, Rubin (2017) levanta um ponto interessante quanto às pré-condições necessárias para a operação dos sistemas de casamento; ela revela a estrutura lógica subjacente à sua análise do parentesco. A organização social da atividade sexual humana estaria duplamente ancorada no gênero e na heterossexualidade compulsória, pois o parentesco instaura a diferença, a oposição, exa-

5 Emma Goldman (1917) 
cerbando, no plano da cultura, as diferenças biológicas entre os sexos. A estrutura protegida é a familiar.

Os sistemas de parentesco envolvem a criação social de dois gêneros dicotômicos, a partir do sexo biológico, provocando a interdependência entre homens e mulheres e a regulação social da sexualidade, prescrevendo ou reprimindo arranjos divergentes dos heterossexuais, ou seja, a homossexualidade e as construções divergentes daquele contexto de família, em que a mulher é a zeladora da casa, dos valores morais e/ou religiosos e da família.

Após essas considerações, retornando ao entendimento de Schettini (20l I) sobre o tráfico de mulheres, as leis regulamentadoras e as que buscavam a supressão do tráfico eram igualmente danosas, pois, postas em ação, iriam contra a vítima, deixando-a nas mãos da ação ilegal e violenta da polícia, considerando que as cruzadas morais terminavam ratificando as ações dos gigolôs. As ideias de Goldman demonstram descrença na interferência legal nessas questões e informam que a solução está no tratamento humanizado às prostitutas e na abolição da escravidão industrial (SCHETTINI, 20 I I , p. 275-277).

Kempadoo (2005), em seu entendimento a esse respeito, refere-se à pesquisa empírica sobre migração, prostituição e atividades em setores informais, que demonstra a relevância da perspectiva feminista e de justiça social sobre o tráfico, pois não se verifica de maneira sistemática que as mulheres sejam sequestradas, acorrentadas às camas em bordéis e mantidas como escravas sexuais ou de outro tipo de trabalho, tendo em vista que o definido num momento como um problema de "tráfico de escravas brancas", atualmente é visto como migração internacional do trabalho e exploração deste, situações aquém do controle dos Estados, tratando-se de crime organizado transnacionalmente, sobre o qual há acentuada vigilância e policiamento globais.

A globalização, o patriarcado, o racismo, os conflitos étnicos, a devastação ecológica e ambiental e a perseguição política e religiosa são fenômenos discutidos com pouca ênfase sobre o paradigma hegemônico do tráfico de seres humanos. Esses problemas estruturais e globais produzem o tráfico de pessoas e ainda são analisados de forma desconexa, o que se deve desconstruir e combater (KEMPADOO, 2005, p. 68).

As feministas transnacionais e os defensores dos direitos humanos demonstram preocupação com o referencial antitráfico adotado pela Organização das Nações Unidas, pois está de acordo com os interesses econômicos e neoliberais das corporações e dos governos nacionais, e não primam pelos interesses dos trabalhadores e populações pobres do mundo. Essas tratativas internacionais requerem que os Estados ofereçam medidas para proteção e assistência às pessoas traficadas; contudo, os envolvidos com traficados asseveram que as violações de direitos humanos não diminuíram com essas medidas. As pessoas traficadas, ainda que sejam tidas como vítimas por essas legislações, têm sido vistas como 
imigrantes ilegais ou criminosos, a não ser que se tornem informantes da polícia e denunciem os algozes.

O crescente número de imigrantes pobres é adicionado ao número de pessoas processadas pelos sistemas de justiça criminal, detidas ou encarceradas por crimes não violentos, como imigração ilegal, uso de drogas e trabalho sexual. As vítimas são passíveis de deportação aos seus países de origem e enfrentam a vergonha e a humilhação, ao mesmo tempo em que são expostas às represálias dos traficantes e ao medo da estigmatização da família e da comunidade, por terem sido envolvidas em atividades sexuais.

A autora informa que suas pesquisas indicaram que os esforços para reprimir a migração trazem consequências mais negativas que positivas e são contra os interesses dos migrantes, pois essas pessoas não querem retornar ao seu local de origem, mas buscam segurança. A ignorância dos governos sobre as razões da migração, as necessidades e os desejos das pessoas que deixam seus países, mesmo que contrabandeados e/ou trabalhem em condições deploráveis, demonstra fuga e/ou vácuo do poder do Estado (KEMPADOO, 2005, p. 69-72).

O crime de tráfico de pessoas reflete uma realidade conhecida historicamente. Retornando séculos, percebe-se que a escravatura foi precursora do crime de tráfico de pessoas, porquanto as pessoas eram deslocadas escravizadas visando desempenhar funções ou atividades contra a sua vontade (GUIA, 20 I 8, p. 17- |8).

A mesma autora ensina que o tráfico de pessoas não atinge apenas migrantes, não sendo condição para a determinação do crime a transposição de uma fronteira internacional; contudo, torna-se fácil ludibriar, enganar e impor a força sobre indivíduos que se encontram em circunstância de vulnerabilidade, como é o caso de parte dos migrantes voluntários ou forçados. Nas duas últimas décadas, o conceito de "fronteira" no espaço europeu sofreu transformações a ressaltar em nível legal, social e até do imaginário coletivo, sobretudo após a implementação dos acordos de Schengen ${ }^{6}$ (p. 20).

Para além desses traços, importa refletir sobre imagens recalcadas há longos anos e que perpassam pela generalidade das sociedades, fruto das desigualdades do poder. Não é comum um indivíduo oriundo dos Estados Unidos da América ser visto como um imigrante, pois a imagem que a maioria da população enxerga como trabalhador com falta de recursos econômicos à procura de uma vida me-

6 Acordos de Schengen: As fronteiras comuns terrestres com os Estados parte na Convenção de aplicação [do Acordo de Schengen, de 14 de junho de 1985, assinada em Schengen em 19 de junho de 1990, cfr. I. h] art $3^{\circ}$ da mesma lei, os aeroportos, no que diz respeito aos voos exclusiva e diretamente provenientes ou destinados aos territórios dos Estados partes na Convenção de Aplicação, bem como os portos marítimos, no que diz respeito às ligações regulares de navios que efetuem operações de transbordo exclusivamente provenientes ou destinadas a outros portos nos territórios dos Estados partes na Convenção de Aplicação (GUIA, 20 I 8, p. 21). 
Ihor é de imigrantes de países não desenvolvidos ou em desenvolvimento. Assim, o estadunidense será visto como alguém que trabalha em área de elevado valor científico ou econômico, pois o inconsciente coletivo concebe mais facilmente aquela primeira imagem do imigrante em busca de melhores condições de vida a um indivíduo oriundo de um país economicamente mais carente, e não o inverso.

A exploração a que são forçadas as vítimas de tráfico de pessoas vai além da exploração sexual. Segundo a autora, há cerca de 21 milhões de vítimas de tráfico de pessoas no mundo, sendo que $79 \%$ das vítimas conhecidas são exploradas sexualmente; desse montante, $66 \%$ são do sexo feminino, e um elevado número dessas mulheres é de cor negra. Assim, essa é a forma de exploração mais visível; entretanto, não é a única (Ibidem, p. 22-23).

Para Martínez Quinteiro (2016); a história do tempo presente assinala novas fronteiras e abordagens a respeito do tráfico de mulheres que possibilitaram que os Estados latino-americanos, a partir da Convenção de Belém do Pará (1994, Brasil) e da Conferência da Mulher em Beijing (1995, China), começassem a implementar e ampliar os esforços para erradicar a violência contra as mulheres. Assim, muitos países que sofreram com ditaduras e outros eventos traumáticos, como os conflitos armados internos, há cerca de 20 anos, têm elaborado políticas públicas com o fim de melhorar as condições de vida de suas cidadãs.

A mesma autora considera que o tráfico de mulheres para fins de trabalhos forçados e prostituição é considerado, junto com o tráfico de drogas e de armas, um dos negócios ilegais mais lucrativos do mundo, que se utiliza de pouco investimento e gera muito lucro, e pela promessa de sucesso econômico seduz as pessoas aliciadas, a quem não necessariamente haverá geração de pagamento, tornando o "negócio" consideravelmente lucrativo.

\section{O TRATADO INTERNACIONAL DE PALERMO E AS REALIDA- DES DO TRÁFICO DE PESSOAS}

Protocolo de Palermo refere-se ao Protocolo Adicional à Convenção das Nações Unidas contra a Criminalidade Organizada Transnacional relativo à Prevenção, à Repressão e à Punição do Tráfico de Pessoas, em especial de Mulheres e de Crianças. Esse tratado internacional visa ao combate ao tráfico de indivíduos entre os continentes para servirem como trabalhadores forçados, até mesmo na prostituição, e, ainda, para deles serem retirados órgãos que serão vendidos no "mercado negro".

Em relação ao continente americano, os encantos por residir no exterior atraem os latino-americanos, até mesmo os brasileiros, os quais são iludidos e aliciados ao acreditarem em propagandas enganosas de trabalho em países economicamente desenvolvidos. Trata-se de propostas veladas e compulsórias de exploração sexual e/ou trabalho escravo. 
O tratado internacional em referência foi elaborado em 2000 e entrou em vigor em 2003, promulgado no Brasil pelo Decreto no 5.017, de 12 de março de 2004. $O$ artigo $6^{\circ}$ do Protocolo obriga os Estados signatários a fornecerem medidas as quais permitam a recuperação física, psicológica e social das vítimas de tráfico de pessoas, em especial alojamento, aconselhamento, informação, assistência médica e material, como também oportunidades de emprego, educação e formação (ONU, 2000).

O Brasil, em consonância com o Protocolo de Palermo, elaborou a Lei $n^{\circ}$ 13.344, de 6 de outubro de 2016, que dispõe sobre prevenção e repressão ao tráfico interno e internacional de pessoas e sobre as medidas de atenção às vítimas (BRASIL, 2016).

Piscitelli (2016), em seu entendimento, refere-se que uma questão remete às formas de governabilidade articuladas nos regimes de combate ao tráfico de pessoas, os quais afetam os intercâmbios forçados de pessoas, particularmente 0 trabalho sexual. A autora questiona se no transcurso do tempo em que houve a promulgação do Protocolo de Palermo (atualmente cerca de 20 anos), quais as questões se delineiam na análise dos regimes políticos quanto ao entrelaçamento de planos supranacionais e seus efeitos nas trocas sexuais e econômicas?

Piscitelli (20 I6) observa que a mercantilização de pessoas não deveria ser um fim analítico, mas o ponto de partida para a análise das relações sociais marcadas por gênero, por significados culturais, por desigualdades sociais e pela busca de transformações nesses aspectos. A ideia é a de que a globalização, além de seus aspectos problemáticos, oferece oportunidades para definir novas modalidades de relações, espaços, significados e expressões de intimidade que podem transformar e transgredir espaços convencionais.

A noção de economias sexuais tem sido formulada e reelaborada academicamente em parte significativa dos trabalhos antropológicos. Essa noção está voltada para a análise de intercâmbios sexuais e econômicos envolvendo pessoas pobres do "Sul global" em geral. Os limites dessa noção podem ser delineados a partir de estudos de diversos recortes empíricos que considerem intercâmbios sexuais e econômicos que envolvam integrantes de diferentes classes sociais e, particularmente, de cidadãos brancos dessas classes no "Norte global".

Nesse ponto, observamos que os países do Sul global, por serem considerados em desenvolvimento, possuem o maior número de pessoas que almejam migrar para os países do hemisfério Norte, por acreditarem que economicamente a vida ficará mais acessível. Esse paradigma fomenta a imaginação dos migrantes e facilita a ação dos aliciadores que traficam pessoas com fins espúrios.

No entendimento de Agustín (2005), os trabalhos forçados que levam à prostituição podem ser considerados não apenas "a prostituição", mas também uma diversidade de trabalhos sexuais, abarcando os trabalhos desempenhados em bordéis, boates, bares, discotecas, saunas, linhas telefônicas eróticas, sexo virtual pela 
internet, casas de massagem, serviços de acompanhantes, agências matrimoniais, hotéis, motéis, cinemas, revistas pornográficas, filmes e vídeos pornográficos com cenas de dominação e submissão sadomasoquistas e comumente a prostituição nas ruas.

Segundo a autora, o termo prostituição, além de ocultar uma diversidade de trabalhos, ainda obscurece a compreensão de que de fato existe um mercado sexual, e isso desvia a atenção do que é criminalizado, do que deveria ser e quais as ações que os Estados devem desempenhar nesses casos. Os crimes estão atrelados ao que se oferece para cumprir a demanda dos diversos desejos das pessoas que procuram por serviços sexuais. No imaginário social, prevalece a ideia de que o sexo deve ser exclusivamente associado ao amor, e isso se torna um empecilho ao tratamento legal adequado para o vasto mercado do sexo, como especificado.

Quanto às prostitutas migrantes, Agustín (2005) entende que, embora não tenham originalmente a intenção de trabalhar na indústria do sexo, elas em geral fazem essa opção consciente, pois muitas alternativas de trabalho no exterior equivalem a não ganhar o suficiente para seu sustento e ajudar suas famílias no país de origem. Essas pessoas não são as traficadas inicialmente, mas as que estão em situação de vulnerabilidade, por isso, passíveis de serem aliciadas pelas quadrilhas que atuam no tráfico de pessoas e, consequentemente, no mercado sexual.

Piscitelli (2016), com referência à disseminação dos regimes de combate ao tráfico de pessoas em diversas partes do mundo, entende que a expansão desses regimes, ancorada numa linguagem de proteção aos direitos humanos, estimularam ações que contribuem para reprimir a migração e combater a prostituição, oferecendo, entretanto, escassa proteção às pessoas consideradas vítimas desse crime. A autora considera que muitos aspectos do tráfico de pessoas são entendidos como dano colateral em termos de direitos e liberdades individuais, pois não colocam as vítimas no centro das respostas no combate ao tráfico de pessoas.

Nesse ponto, critica-se que apenas o enfoque de direitos humanos é ineficaz para neutralizar os aspectos problemáticos do tráfico de pessoas considerados atualmente como danos colaterais. Esses aspectos estão presentes no Protocolo de Palermo, que, segundo a autora, demonstram uma aparente tensão entre o combate ao crime, à migração irregular e à proteção às vítimas. Ainda, considera que há uma distância entre os elaboradores de políticas de combate a esse crime e as subjetividades a que se referem.

Piscitelli (2016) entende ser importante considerar o impacto generativo do Protocolo de Palermo na produção de medidas de combate ao tráfico de pessoas regionais e locais, pois as leis nacionais não possuem potencial para gerar medidas criativas ou repressivas ao tráfico de pessoas, como ampliar as conceitualizações deste tráfico, indo além das intenções dos elaboradores do Protocolo de Palermo, investigando adoções fora dos parâmetros éticos, mendicidade, envolvimento for- 
çado de pessoas em atividades criminosas, uso de pessoas em conflitos armados, sequestros com fins de extorsão ou de terrorismo político, entre outras ações que poderão ser entendidas como tráfico de pessoas.

O tratado internacional, conhecido como Protocolo de Palermo, muito contribuiu para a visibilidade desse crime que se inicia num território e exaure seus resultados noutro, até mesmo de maneira permanente. $O$ esclarecimento dessas ações criminosas às sociedades e o combate podem ocorrer desde a elaboração de legislações nacionais e regionais que considerem a realidade econômica de Estados fronteiriços como quanto à elaboração de convênios entre países de continentes diferentes.

A realidade cultural e econômica dos Estados acaba por influenciar na prática do crime de tráfico de pessoas com a finalidade de forçar trabalhos e embutir as práticas de prostituição; portanto, a legislação doméstica dos Estados em muito contribuirá com as ações positivas contra esse crime, importando que aspectos significativos e singulares de sua população sejam considerados na legislatura contra esse fenômeno e na elaboração de políticas públicas.

Os aspectos a serem valorados socialmente pelos Estados envolvidos na problemática do tráfico de pessoas são: a cultura social, com suas crenças e valores; o índice de desenvolvimento humano; o índice de pobreza ou riqueza; o produto interno bruto anual, entre outros.

Desse modo, além do clamor das violações de direitos humanos, por exemplo, países de herança patriarcal poderão contar com legislações nacionais endurecidas quanto à violência contra as mulheres, o que refletirá em outra ponta nas migrações forçadas e forçosas, em âmbito nacional e internacional, de meninas e mulheres.

\section{CONSIDERAÇÕES FINAIS}

O reconhecimento da voz das mulheres em sociedade não necessita de que as manifestações dos homens inexistam, mas implica compartilhamento do espaço social, e isso exige cessões, cooperação e consequentemente transformações no poder do patriarcado para a total dissolução do paradigma de fragilidade ou inferioridade "natural" da mulher perante o homem. A mobilidade social das mulheres tem contribuído para a modificação desse panorama.

A violência simbólica e a dominação masculina ainda persistem no cenário das sociedades ao redor do globo, em algumas mais, em outras menos, em que pese à tensão da moral social de cada país. A mobilidade social das mulheres rompeu muitos paradigmas, até mesmo em relação ao corpo da mulher; entretanto, isso não impediu que a mulher fosse vítima de tráfico para trabalhos forçados que levem à prostituição. As mulheres conquistaram o direito ao espaço público; todavia, não a unanimidade do respeito por esse direito. 
○ crime de tráfico de pessoas é considerado uma violação aos direitos humanos. Esse crime de escravizar pessoas e de as deslocarem para fins de trabalhos forçados já foi considerado um negócio. As épocas passaram e a modificação cultural dos espaços se fez. Desse modo, essa dinâmica passou a ser execrada, como tantos outros valores se transformaram. Certo é que esse crime não atinge apenas migrantes, mas sobretudo indivíduos em situação de vulnerabilidade.

A exploração a que as pessoas são forçadas vai além da exploração sexual, pois as vítimas são expostas a humilhações, preconceitos, locais inadequados e insalubres para o alojamento forçado, precariedade no atendimento de saúde, alijamento da sociedade, entre outros efeitos considerados colaterais no trato jurídico do tráfico de pessoas.

Os sistemas de proteção dos direitos humanos por meio de seus acordos internacionais buscam a melhora da situação de vulnerabilidade global e o enfrentamento das problemáticas que envolvem violência contra a mulher e consequentemente o tráfico de mulheres para fins de trabalhos forçados e prostituição; contudo, é um crime que invade a vida da vítima e a de seus familiares, o qual levanta elevado capital com pouco custo para os traficantes, está encoberto das sociedades por preconceitos e ilegalidades.

Como é um crime complexo, com vítimas diretas e indiretas, praticado por quadrilhas de traficantes que trabalham em redes, por vezes despersonificados, é necessário que as políticas públicas trabalhem muito na prevenção, com esclarecimentos sobre as abordagens dos aliciadores às vítimas; que envolvam a educação como formação; promovam a eficácia dos órgãos fiscalizadores das empresas de transportes de pessoas; e, na outra ponta, contem com a segurança pública e a justiça aparelhadas e preparadas tanto para romper com a tentativa de tráfico como para investigar e aplicação punições.

Para que seja possível a elaboração de políticas efetivas, nesse contexto, há necessidade de os Estados trabalharem com as discrepâncias e as sutilezas desses crimes em suas legislações nacionais, considerando o contexto de suas sociedades, e até adotando medidas entre Estados fronteiriços terrestres que possuem pontes por meio de portos e de aeroportos.

É importante que haja um trabalho de base pautado nas subjetividades desses indivíduos, como, por exemplo, um resgate histórico-social e a significação do papel da educação em direitos humanos nesse mesmo contexto, exaurindo o cumprimento das metas estabelecidas pelo Protocolo de Palermo.

Os estudos deram conta de que a vigilância social sobre o corpo da mulher sofreu rupturas mais efetivas a partir da metade do século $X X$, e o modo de ser feminino foi relativizado, possibilitando trânsitos das mulheres nos espaços sociais.

A conquista de uma gama de direitos das mulheres e positivação de leis, em que está pautado o Protocolo de Palermo, discutido e elaborado no início do século $X X \mathrm{X}$, como consequência de ações tomadas por movimentos de mulheres 
em todo o século $X X$, não garantiu o respeito social público, o qual ainda não se solidificou, e a violência contra as mulheres persiste no poder simbólico social explicado pelo pensador Pierre Bourdieu.

As ações pautadas internacional e nacionalmente, com vista ao enfrentamento do tráfico de pessoas, nesse foco, meninas e mulheres em um contexto de vulnerabilidade, poderão intensificar-se e materializarem-se da mera positivação em ações coletivas dos Estados, de modo preventivo e educacional, antes de perpetrarem forças punitivas, engendrando esforços na máquina administrativa correcional.

As conquistas femininas em matéria de direitos são consideráveis desde a metade do século $X X$, as quais tornaram a vida social das mulheres possível e acessível, mas há muito trecho a percorrer do que foi iniciado pelas antecessoras e defensoras dos direitos das mulheres. Há valores a serem conquistados, como reconhecimento e respeito, sem carecerem obrigatoriamente da pressão legislativa para serem concedidos.

\section{REFERÊNCIAS}

AGUSTÍN, Laura. Trabajar en la industria del sexo, y otros tópicos migratorios. Tercera Prensa, Donosti, 2005.

BAUMAN, Zygmunt. Modernidade Líquida. Tradução de Plínio Dentzien. Rio de Janeiro: Jorge Zahar, 200 I.

BEAUVOIR, Simone de. O segundo sexo. Versão digital. 2. ed. Rio de Janeiro: Nova Fronteira, 2009.

BOURDIEU, Pierre. A dominação masculina. Trad. Maria Helena Küher. 2. ed. Rio de Janeiro: Bertrand Brasil, 2002.

O poder simbólico. Tradução de Fernando Tomaz. Lisboa. Rio de Janeiro: Bertrand Brasil, 1989.

BRASIL. Lei no I I.340, de 7 de agosto de 2006. Lei Maria da Penha. Cria mecanismos para coibir a violência doméstica e familiar contra a mulher, nos termos do $\S 8^{\circ}$ do art. 226 da Constituição Federal, da Convenção sobre a Eliminação de Todas as Formas de Discriminação contra as Mulheres e da Convenção Interamericana para Prevenir, Punir e Erradicar a Violência contra a Mulher. Diário Oficial da União. Brasília, 8 ago. 2006. Seção I, p. I. 
. Lei n 13.344 de 06 de outubro de 20 | 6. Dispõe sobre prevenção e repressão ao tráfico interno e internacional de pessoas e sobre medidas de atenção às vítimas. Diário Oficial da União. Brasília, 07.out.2016. Disponível em: http:// www.planalto.gov.br/ccivil_03/_ato20 I5-2018/2016/lei/LI3344.htm. Acesso em: 20 jan. 2020.

CASTILHO, Ela Wiecko V. de. A criminalização do tráfico de mulheres: proteção das mulheres ou reforço da violência de gênero? Cadernos Pagu (3I), julho-dezembro de 2008: | 01 - $\mid 23$.

GUIA, Maria João. Sete ligações perigosas entre imigração e tráfico de pessoas. Mulheres invisíveis: panorama internacional e realidade brasileira do tráfico transnacional. SMANIO, Gianpaolo P. et al (Orgs.). Curitiba: CRV, 20 I8.

GOLDMAN, Emma. The tragedy of woman's emancipation. In: Anarchism and other essays, 1917. Disponível em: http://womenshistory.about.com/library/ etext/bl_eg_ana_tragedy_womans_emancipation.htm. Acesso em: 2 set. 2019.

IRIGARAY, Luce. Este sexo que não é só um sexo: sexualidade e status social da mulher. São Paulo: Senac, 2017.

JUNG, Carl Gustav. Os arquétipos e o inconsciente coletivo. Tradução de Maria Luíza Appy e Dora Mariana R. Ferreira da Silva. Petrópolis - RJ: Editora Vozes, 2. ed. 2002.

KEMPADOO, Kamala. Mudando o debate sobre o tráfico de mulheres. Cadernos Pagu, n. 25, p. 55-78. Campinas: Núcleo de Estudos de Gênero - Unicamp, 2005. Disponível em: https://periodicos.sbu.unicamp.br/ojs/index.php/cadpagu/ article/view/864470I. Acesso em: 24 abr. 2019.

KERGOAT, Daniéle. Divisão Sexual do Trabalho e Relações Sociais de Sexo. In. HIRATA, Helena et al. (Org.). Dicionário Crítico do Feminismo. São Paulo: editora UNESP, 2009, p. 67-75.

LAGARDE Y DE LOS RÍOS, Marcela. Los cautiverios de las mujeres: Madresposas, monjas, putas, presas y locas. San Cristóbal: horas y HORAS, 201 I.

LEGARDINIER, Claudine. Prostituição I. In. HIRATA, Helena et al. (Org.). Dicionário Crítico do Feminismo. São Paulo: editora UNESP, 2009, p. 198-203. 
MARTÍNEZ QUINTEIRO, Maria Esther. Nuevos abordajes del tráfico de personas. In: II Ciclo de Conferências Internacionais - O crime organizado e o tráfico de pessoas - reflexões e dilemas internacionais, Coimbra: Instituto Superior Bisaya Barreto, 2016, p. 125-133.

. La trata de personas, un grave atentado contra los derechos humanos y un desafío para la comunidad internacional. In: Aguilera Urqiza Antonio Hilario (Org.). Nascimento: os direitos humanos nas fronteiras (Brasil e Europa). UFMS, 2016, p. $145-159$.

OLIVEIRA, Adriana Ferreira Serafim de. As políticas públicas de enfrentamento á violência contra a mulher na legislação e nos depoimentos. São Paulo: Editora Unesp - Selo Cultura Acadêmica, 2020.

ORGANIZAÇÃO DAS NAÇÕES UNIDAS (ONU). Carta das Nações Unidas de 1945. Disponível em: https://brasil.un.org/pt-br/9|220-carta-das-nacoes-unidas. Acesso em: 13 abr. 2021.

. Protocolo Adicional à Convenção das Nações Unidas contra a criminalidade organizada transnacional relativo à prevenção, à repressão e à punição do tráfico de pessoas, em especial de mulheres e crianças (Protocolo de Palermo). ONU. Nova lorque: ONU, 2000. Disponível em: http://www.planalto.gov.br/ ccivil_03/_ato2004-2006/2004/decreto/d50 I7.htm. Acesso em: 4 maio 2020.

PATEMAN, Carole. O contrato sexual. São Paulo: Paz e Terra, 1993.

PISCITELLI, Adriana. Economias sexuais, amor e tráfico de pessoas - novas questões conceituais. Cadernos Pagu, 20 I 6. Disponível em: https://www.scielo.br/scielo.php?script=sci_arttext\&pid=SO | 04-833320 | $600020040 \mid$ \&lng =pt\&tIng=pt. Acesso em: 20 maio 2020.

RUBIN, Gayle. Políticas do sexo. Trad. Jamille Pinheiro Dias. São Paulo: Ubu Duke University Press, 2017.

SCHETTINI, Cristiana. Emma Goldman e a experiência das mulheres das classes trabalhadoras no Brasil. In: Cadernos Pagu (37), julho-dezembro de 201 I : 273 285.

Disponível em: http://www.scielo.br/pdf/cpa/n37/al In37.pdf. Acesso em: 25 abr. 2019. 
SAFFIOTI, Heleieth. Gênero, Patriarcado, Violência. 2. ed. São Paulo: Expressão Popular, Fundação Perseu Abramo, 2015. 


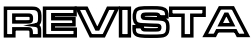

ESMAT ADRIANA FERREIRA SERAFIM DE OLIVEIRA / PATRÍCIA TUMA MARTINS BERTOLIN /
MARIA ESTHER MARTÍNEZ QUINTEIRO

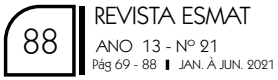

